\title{
CAPP as a tool for strategy development of competitiveness in the mechanical engineering industry within European countries
}

\author{
Katarina Monkova ${ }^{1}$, Peter Monka ${ }^{2,3}$, Helena Zidkova ${ }^{3}$
}

\begin{abstract}
The article deals with the possibilities of CAPP utilization as a tool for the development of competitiveness between mechanical engineering enterprises within European countries. The process planning activities are significant for company flexibility, product delivery time to market and competitive advantage of enterprise. The process planning system inside an industrial plant is therefore important tool for increasing of product quality, efficiency and also its profit. Nowadays, in many East European countries, it is needful to use the strategy of Product \& Manufacturing Design for application of modern processes along with using computer aid of process planning. When designing the new product, the aim is to secure or increase its technical value not only by systematization of the production process but also by increasing the level of the supporting tools for the rational processing of the production documentation and data needed for planning. Described principles of CAPP system, newly designed by authors, could be the first step to the company's competitiveness increasing and also to its integration to "Industry 4.0".
\end{abstract}

Key words CAPP, competitiveness, mechanical engineering industry, information system

\section{Introduction}

In 2010, the European Commission (EC) proposed the Europe 2020 strategy as a means of focusing the European Union (EU) and its Member States on the important task of improving the EU's competitiveness. According to the strategy, its goal is to transform the EU into "a smart, sustainable and inclusive economy, delivering high levels of employment, productivity and social cohesion." Today, with the acute phase of the economic and financial crisis in the past, and with

\footnotetext{
${ }^{1}$ Department of Computer Aid of Manufacturing Technologies, Faculty of Manufacturing Technologies with the seat in Presov, Technical University of Kosice, Kosice, Slovakia, katarina.monkova@tuke.sk

${ }^{2}$ Department of Manufacturing Technologies, Faculty of Manufacturing Technologies with the seat in Presov, Technical University of Kosice, Kosice, Slovakia, peter.monka@tuke.sk

${ }^{3}$ Department of Machining Technology, Faculty of Mechanical Engineering, University of West Bohemia, Pilsen, Czech Republic, zidkova@kto.zcu.cz
} 
signs of moderate but uneven growth and sluggish job recovery amid a number of risks and fragilities in Europe, it is critically important to create renewed momentum around the long-term structural shifts required to meet these goals. At the heart of competitiveness is the level of productivity of an economy. As such, competitive economies are those that are able to provide high and rising living standards, allowing all members of a society to contribute to and benefit from these levels of prosperity. In addition, competitive economies also have to be sustainable - meeting the needs of the present generation while not compromising the ability of future generations to meet their needs [1].

Addressing the competitiveness divide will require differentiated strategies that take national and regional characteristics into account. While a concerted and united effort is desired from all EU Member States to improve Europe's knowledge driven economy, it is clear from the large regional disparities that paths towards this goal, and priorities for improvement, will differ across countries. For instance, innovation strategies for countries higher on the knowledge ladder will differ from strategies appropriate for countries lower down. However, for all European economies, investments in knowledge-generating assets will translate into important drivers for future productivity growth - those drivers being a common focus on education, information and communication technologies, the digital agenda and reforms to improve the overall enterprise environment across the region $[2,3]$.

Many of East European (EE) post communism countries were forced to transform their production schedule, quantity, types and kinds of products after political transformations. But lot of plants in these countries are working with unchanged philosophy up to this day. This is one of the reasons why numbers of plants are still out of competition in comparison with west plants despite of cheaper manpower. Basic problems in EE plants are [4,5,6]:

- low level of information technology (live data, information availability and uniformity of structures),

- the computer aid has unsystematic character; there are used only subprograms, mostly at difficult, often incompatible, computing systems in Slovak plants,

- absence of the tools, which makes it possible to analyze of dynamic system properties important for the planning of high automation system at short time,

- missing tools for alternative solutions, including possibilities of their testing and optimization,

- isolation between project, realization and running system in phase of design with dominate routine labor.

The transformation or development of ESE production enterprises to new European environs is a complex process. Producers are permanent pressed by increasing domestic and foreign competition. One of efficiently way of competitiveness enhance is related to advanced application of the computer aided (CA) systems. CA systems are sophisticated solutions which cover all areas of company activities. They integrate requisite information and provide live data that are necessary for efficient labor-saving work and for the receiving sufficient decisions. 


\section{Impact of European market composition to CAPP design}

Great number of East European companies has different process planners make different process plans for the same parts, resulting in inconsistencies and extra paper work and are applied in heterogeneous data environ [7]. Computer Aided Process Planning (CAPP) systems can help in overcoming these inconsistencies. CAPP aids in creation of process plans for manufacturing and increases the flexibility of manufacturing. Process planning is a task which requires a significant amount of both time and experience. Computer support or computerized process planning systems can help reduce a process planning time and increase plan consistency and efficiency.

In the history of Computer Aided Process Planning (CAPP) generally two different ways of obtaining the process plan can be observed [8]:

- variant process planning,

- generative process planning.

Generally, process planning systems are oriented to one of this way. But each technique it features with some advantages. Exploitation benefices of one of both can be obtaining by help combination of them.

When applied some of technological approach, it is advantageous to subdivide complete process within a production company into problem-orientated system areas, which represent a limited area of activities. The formulated scheme of plant shown in Fig. 1 [6] represents the first assignment stage for building concept of production information system. The specific tasks and activities of the production process are focused on:

- Design,

- Process Planning,

- Manufacturing and Assembly.

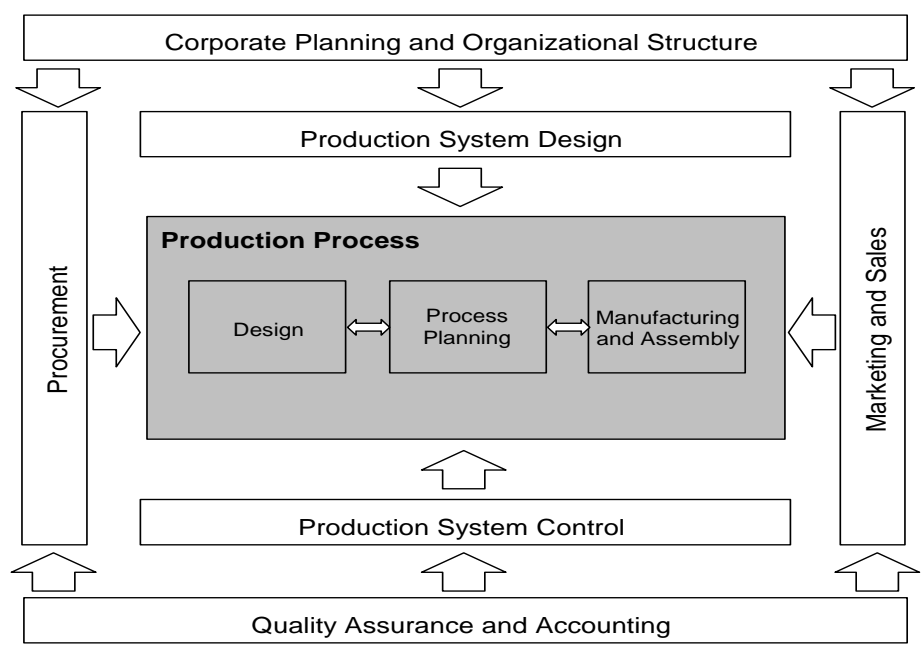


Fig. 1 Principal scheme of plant [6]

These tasks form the basis for the realization level of the corporate objective of design this information system. The direct system areas, which are subdivided into a field of Production System Design and Production System Control, are grouped around this realization level of production processes $[9,10]$.

The indirect system areas cover the external influential factors of the corporate process [11]:

- corporate planning and organizational structure deals with the long-term and mid-term planning of corporate aim and the resultant structurizing of the corporation to reach the planned objective,

- production system design has the task of attuning the methods and processes, which contribute to the rational realization of the technical and economic overall objective in design, process planning and manufacturing.

- procurement deals with the optimum material arrangements in respect of times and costs,

- marketing and Sales covers the comprehensive marketing and sales promotion systems,

- quality assurance and accounting systems are auxiliary aids for the control function of the technical and economic corporate function of the technical and economic corporate objectives.

- production system control is to optimize the throughput times of the orders.

The objective of product design is to raise or assure the technical value of product not only in the systemization of the design process, but also in the build-up of work aids for the rational elaboration of drawings and planning data. Thus, the term product design describes the comprehensive application of methods and work aids during the design process of a product to the release of the basic data for process planning. The objective of manufacturing design is to systemize the planning and preparation processes for the manufacture and assembly and to build up the planning data for the rational realization of the different partial assignments within the framework of the concept. The aim of work study and wage structure is to optimize the working conditions at the work place and to increase output in accordance with scientific methods and processes [12]. 


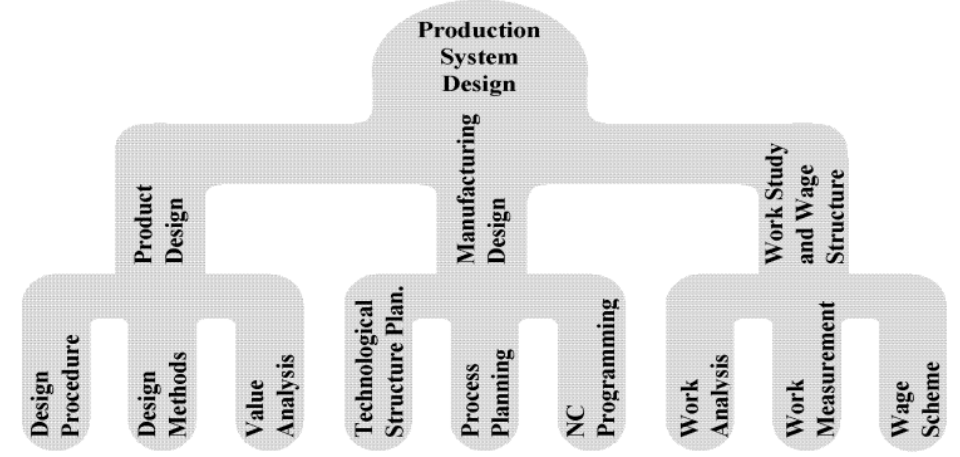

Fig. Structural concept of information system

On the basis of these objectives, a structural concept according to Fig. 2 was developed for the information system of production system design in the field of mechanical engineering. They constitute the basic form for further database structure building and for creation of mathematical model of manufacturing system. In this system is possible formularized manufacturing system by relation:

$M S=S \bigcup S O \bigcup E$

where:

$M S$ - Manufacturing System,

$S$ - Segment,

$S O$ - Structure of Operation,

$E$ - Equipment.

Every set from relation (1) is possible to split on subsets and each subset is possible to divide on sub-subsets of lower and lower layer. Depth of set definition (and circumstantial of described details of storages data) is dependent on required optimization and variation rules. In describes project it was used the layer of set depth for description basic properties of every registered object in database. This concept enables very good conditions for application of mathematical tool for manufacturing planning and registration all relevant data.

A basic research about the composition of European market in Fig. 3 [13] shows very interesting summaries - typical European enterprise unit is micro enterprise. This kind of companies constitute a substantial part of the European market as they comprise 92 per cent of the overall number of companies and employ 39 per cent of the employees. Small and medium size companies together comprise 7.5 percent of the overall number and employ 30.3 per cent of the employees. The rest ( 0.2 per cent production unites and 30.2 per cent employees) is covered by large companies. Other results of this same study show that micro companies have the disposal of a free potential of 20 per cent of the productivity and 15 per cent profitability. 


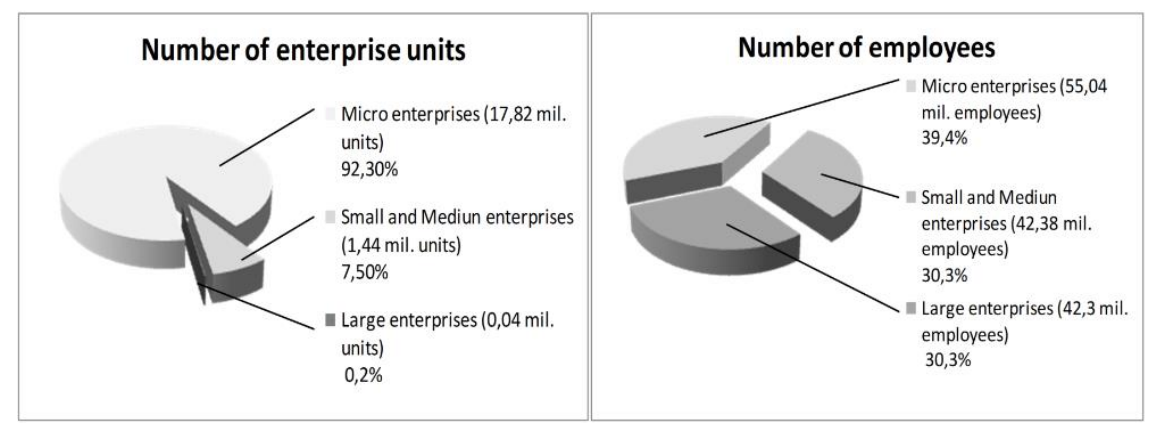

Fig. 3 Structure of business units in the European Union [13]

These characteristics which describe a distinct ability of the dynamic growth production and the possibility of effective evaluation of micro company instruments are very important.

On the basis of the analysis of potential system users securing the computer support of the computer aid process planning, it can be said that it is the micro companies that constitute the significant part of the enterprise subjects.

\section{Design of CAPP system}

The specifications of enterprise units' structure imply diametrically different demands on information systems from the view of micro and small size companies and the medium or large size companies. They are:

- simple implementation,

- possibility of modular concept for covering all necessary areas,

- reliable and secure data formats and structures,

- possibility of flexible data sharing with IS (Information System) of the purchaser and supplier,

- possibility of a trouble-free extension to the needed modules,

- securing the possibility of a relatively fast transfer to IS higher levels when necessary,

- reasonable price (last but not least).

From the point of view of the information system constitution, one of the basic demands is the security of the possibility of creating the information relation between the enterprise unit subjects on the European market in the way the exchange of the required information in a data way is secured.

From the point of view of the demand variety of the individual companies, the conditions were assessed when proposing IS:

- the system must be able to work with the possibility of the user view on the production process from several angles, 
- enterprise subject should be limited when launching new products to the production process as little as possible,

- it should be applicable for a wide range of business,

- it should be modular.

The requirement to find such information system, which is adapted to East Europe market conditions, brings the idea to create new system. For this system were specified some basic requirements:

- it has to be able to do from several viewing angles,

- it hasn't to restrict new products at their put on the manufacturing process.

Therefore, the system was built for possibility of combination on the basis of the following technological approaches: [14-16]

- Individual technology (IT),

- Type technology (TT),

- Group technology (GT).

Designer can choose best approach for process planning of production object.

The Individual approach includes the creating of manufacturing documentation for each component individual without the possibilities to use the same repeated operations for certain set of manufacturing objects (from parts through subassemblies and assemblies to final products). It can be said that his approach is not connected with standardization of technological processes and with the activities linked with them.

The term Type technological process represents the specific technological process for group of parts with the equivalent technological characteristics. This process is suitable for specific group of parts and defines the type and the sequence of main technological operations. The important term for Type technology is The Type Representative. It's real or abstract object of manufacturing, which technological process contains all basic and auxiliary operations existed in this group of parts. The typification of technological processes can be realized by two methods that are varying in the usage and in the objects of classification. The following proceeding is typical at the typification of technological processes: [17]

1. classification of parts (or the elementary surfaces),

2. projection of the Type technological process (operation),

3. specification of individual technological process phases,

4. development of technological process for the Type representative,

5. transmission of Type technological instruction to specific part.

Another type of technological processes standardization is the Group technology. It is manufacturing philosophy and strategy that assists a company in understanding what it manufactures and how those products are then manufactured. In manufacturing engineering, Group technology focuses on similar machining operations, similar tooling, machine setup procedures and similar methods for transporting and storing materials. [18] 
By identifying similarities in manufacturing (machines, tooling, process sequences, etc.), similar work pieces' parts (geometric shape and size) can be grouped into distinct families and processed together in dedicated work cell. Some parts may look similar to each other, but because of differences in materials, tolerances or other production requirements, they have different manufacturing conditions and so don't create "manufacturing family of parts". In contrast to Type technological processes, the Group process is always specific and it serves as technical instruction to realize individual operations. The approaches to Group technology are today based on the fact that all technical and organizational evolutions inside specific manufacturing unit contain activities or data with some degree of similarity. So they can be combining into the groups for which are used common solving and methods. The methodological tools for the sorting of parts are different classification and coding systems.

\section{Multi-variant process planning}

Essential ambition of authors was build-on a basic structure for CAPP system which is very flexible from the views:

- creating and modifying versions of process plans;

- approach of design processes;

- sharing data among members of manufacturing chain;

- modularity of components required by user;

- possibility of cooperation with wide variety of external software.

According these basic claims theory of multi-variant process planning was designed. The theory deals with the production process (during its project phase, also during the production) as a homogenous whole, including technological and labor processes organized via various possible parallel phases in the way the final product could be processed in the optimized way for the set conditions whilst fulfilling all the demands required by a consumer. On the basis of this theory it is possible to create combination possibilities of various techniques used in individual process planning based on the strategy aimed at achieving the specific goal of the production unit. The main objective of this theory is:

- the creation of the unified definition environment for all the factors immediately influencing the result of production process

- the flexible interface which enables bidirectional exchange of the required information with all surrounding systems.

Via the unified definition environment, the philosophical and conceptual unity is secured within the whole issue falling into the formation area of multi-variable process planning, a distinct classification product constituent and the laws of production sequence for operation projection which allow the use of several possibilities designed by information system based on this theory. 
Flexible interface of the system must enable an effective work in the production environment in the way all the individual relevant systems creating heterogeneous information system (CAD/CAM application, wage records, accounting, material management, ...) have the inter-connection secured via the suitable interfaces in order to prevent the errors caused by data redundancy, human factor, but also to reduce the response time to a minimum.

The following steps were created by means of database system Users rules for definitions of rights, Queries for selecting required data, Forms for data editing by operators, Reports for exploring of relevant data, Procedures for operation with data.

For correct database working is required fill all relevant information to interface for storing properties and characteristics of production segment. Under term "segment" is for purpose of this information system mean all manufacturing objects from part, through subassembly and assembly groups to final product). This interface is asking for basic information about production segment and further indications.

Procedures about this system has to be worked out by operators with knowledge about advantages and disadvantages every strategy, which can be used for processing of production segment. In frame of this phase it is possible to prepare the classification of this segment for future handling as well as possible in manufacturer conditions.

After imputing all relevant information - production segment data and classification - is information system ready for definition of manufacturing characteristics

It is possible for operator to create more process plans suitable for actual production segment. For example, for every hypothetic event, which is able to occur in the future, the operator creates one process plan with equivalent strategy, or in case of new unpredictable state it can be worked out new strategy. Basic varieties of prepared process plant are worked out for example for these cases:

1. maximal efficient,

2. minimal cost,

3. change of products flow (in occurrence of use to full capacity machine tools).

It is possible to define more phases inside every process plan. Every phase is relative independent line of operations. For example, the first phase may be the casting, the second - machining and the last one - surface treatment.

In the frame of phase, the operator may work out manufacturing sequence in these ways:

1. handle writing of technological operation cycles,

2. NC program - direct writing by operator or established for group in frame of GT or downloaded from NC program creator ...

3. sequence of operation pictograms,

4. simulation sequence (video, animation, ...).

Really tested Multi-Variant Process Planning system was originated by interconnections for wide variety of CAD/CAM systems (models, CL data \& NC pro- 
grams etc.) and various methods of technological approaches for multi-variant process plan design correspondent to requests of European plants.

\section{Conclusion}

On the basis of the aforementioned theory characteristics, information system was created and applied into real production conditions in the computer aided process planning. Product designed with CAPP consists of approximately 6000 components.

The given product was a result of the co-operation between a German company, providing investments and co-operation of the activities, and Slovak companies providing a technical process planning and the production of a final product.

From the very beginning of the project the established IS served for a suitable analyzing of individual real database objects (components, substructures, structures, finished product), i.e. new analytical tools were created when required.

Established solution serves the purpose of easier and faster assigning of the process parameters, shortening of the computer aided process planning documentation time in real production conditions, and it also supports the effective utilization of the production plant based on the model mathematical description of object variation of the computer aided process planning, fulfilling the combination of the required characteristics within the given production conditions. Output system data can be used for processing of the details for the warehouse, economic and wage records as for their control and optimization.

The main contributions of assigning IS, elaborated on the basis of the multivariable process planning in the real manufacturing conditions, can be summarized into reduction of the variability of warehouse stock (at the first application by nearly 30 per cent); immediate information about the product elaboration; fast acquisition of the details via interfaces for the wage records and accounting; flexible analytical tools enabling the adoption of better decisions and acquisition of the statistical values of parameters applicable to plan production in the future.

The software tool is created in the way to be easily implemented to an already existing information company structure via flexibly adjustable interfaces. It is also user-friendly, developed with the characteristics of GUI, typical for OS MS Windows, so that the basic grasp of its functional working does not require expensive trainings. Of course, if the maintenance of this system is to be productive, it must be familiarized with the given philosophy and possibilities of tactic and strategy planning, through which the production can be optimized.

Presented manufacturing information system is unique in possibility cooperation by CAD/CAM system (practically with any from known) and connectivity to other systems (accounting, stock, wages etc.). This concept brings advantages manly for micro companies. They are related to the Modular conception; Flexible interconnections to partners; Possibility of cooperation with wide variety of external software and Convenient price level. 
All practically know-how of described system shows new tasks for future research of authors in the following scopes:

- investigation of a system for comparison of 3D data to find the objects similarity,

- looking for the better interfaces for CL data creation, NC program sharing, alerts about 3D model changing etc.,

- seeking certain data formats for communications between cooperated plants,

- research of general format of process plan data,

- investigation of production environs in other European countries.

\section{Acknowledgments}

The paper originates with the direct support of Ministry of Education of Slovak republic by grants VEGA 1/0614/15, KEGA 087TUKE-4/2015 and thanks to project ED2.1.00/03.0093 Regional Technological Institute covered by the European Regional Development Fund and the state budget of the Czech Republic.

\section{References}

[1] Schwab, K. et al.: The Europe 2020 Competitiveness Report: Building a More Competitive Europe, World Economic forum, Insight report, Geneva, 2014

[2] Dobransky, J. et al. (2016) Optimization of the production and logistics processes based on computer simulation tools, Key Engineering Materials, Volume 669: pp. 532-540

[3] Ungureanu, M. et al. (2016) Innovation and technology transfer for business development, Procedia Engineering, Volume 149: pp. 495-500

[4] Hloch, S. et al. (2008) Experimental study of surface topography created by abrasive waterjet cutting, Strojarstvo. Volume 49(4): pp. 303-309

[5] Panda, A. et al. (2014) Progressive technology - Diagnostic and Factors Affecting to Machinability, Applied Mechanics and Materials, Volume 616: pp. 183-190

[6] Monkova, K., Monka, P. (2014) Newly developed software application for multiple access process planning, Advances in Mechanical Engineering, Vol. 2014, article number 539071

[7] Krolczyk, G.M. et al. (2014) Influence of technological cutting parameters on surface texture of austenitic stainless steel, Applied Mechanics and Materials, Volume 693: pp. 430 - 435

[8] Kuric, I. et al. (1999) Computer Process Planning in Machinery industry, Technical University Lodz, Bielsko-Biala, Poland

[9] Stoicovici, D. I. et al. (2008) An experimental approach to optimize the screening in the real operating conditions, Manufacturing Engineering, Issue 2, 2008, Technical University of Kosice, 2008, pp. 75-78

[10] Krehel, R. et al. (2016) Diagnostic analysis of cutting tools using a temperature sensor. Key Engineering Materials, Volume 669: pp. 382-390

[11] Jurko, J. (2011) Verification of cutting zone machinability during the turning of a new austenitic stainless steel, Advances in computer science and education application, Volume 202(2): pp. 338-345

[12] Krehel, R. et al. (2009) Mathematical model of technological processes with prediction of operating determining value, Acta Technica Corviniensis: Bulletin of Engineering, Volume 2(4): pp. $39-42$

[13] Ackerman J. (2007) Ps Structures and Production Plants in Competence Cell-Based Networks, Advances in Production Engineering, Warsaw 
[14] Suresh N.C., Kay J.M. (1998) Group technology and cellular manufacturing: State-of-theArt Synthesis of Research and Practice, Kluwer Academic Publishers, Massachusetts, pp. $568-572$

[15] Cesakova, I. (2014) Evaluation of cutting tool parameters, Procedia Engineering, Volume 69: pp. $1105-1114$

[16] Baron, P. et al. (2016) Proposal of the knowledge application environment of calculating operational parameters for conventional machining technology, Key Engineering Materials, Volume 669: pp. 95-102

[17] Ferroudji F. et al. (2014) Large-scale Dual Axis Sun Tracking System Modeling and Static Analysis by FEM, International Journal of Mechanical \& Mechatronics Engineering, Vol. 14 (04) pp. 92-97.

[18] Cep, R. et al. (2011) Testing of greenleaf ceramic cutting tools with an interrupted cutting, Technical Gazette, Volume 18(3): pp. 327-332 